\title{
Desenvolvimento de um software para calibração de trenas utilizando visão computacional
}

\author{
Matheus Santana Carvalho \\ matsantana27@gmail.com \\ Universidade Federal de Santa \\ Catarina - Campus Joinville \\ Joinville, SC
}

\author{
Benjamin Grando Moreira \\ benjamin.grando@ufsc.br \\ Universidade Federal de Santa \\ Catarina - Campus Joinville \\ Joinville, SC
}

\author{
Sueli Fischer Beckert \\ sueli.f@ufsc.br \\ Universidade Federal de Santa \\ Catarina - Campus Joinville \\ Joinville, SC
}

\begin{abstract}
Metrology is responsible for the studies of aspects that involve the measurements application, being a common area to engineering in the search for continuous improvement and quality in the process and products. To approximate the machine processing, factory floor, and development of new applications, continuous technological development is demanded from the industrial sector and modernization of its process. In this scenario, Metrology 4.0 uses technologies in the traditional process ensuring the data quality, reliability, and supports decision in real-time. For the innovation of the traditional models of calibration, this paper introduces a software development to realize the comparation of measuring tape with a standard, using Computer Vision, and compares the results of this process with the traditional calibration methods.
\end{abstract}

\section{PALAVRAS-CHAVE}

Visão computacional, Calibração, Metrologia 4.0

\section{INTRODUÇÃO}

A metrologia é a ciência responsável pelo estudo teórico e prático dos conteúdos que envolvem as medições e suas aplicações, sendo considerada importante para o desenvolvimento da competitividade e da inovação. Alguns dos seus principais focos são a confiabilidade e a qualidade das medições, itens importantes em qualquer sistema de medição [1].

A calibração, por sua vez, é uma operação realizada diariamente em laboratórios de calibração e ensaios por todo o mundo e trata-se de um processo regulamentado, sob determinadas condições, para a determinação do erro e da incerteza de medição de um instrumento quando comparado com um valor de referência [4].

A utilização cada vez mais crescente de tecnologias e internet no setor industrial, resultou no desenvolvimento da quarta revolução industrial, mais conhecida como Indústria 4.0. O termo ficou amplamente conhecido após a publicação de um conjunto de ações para a indústria e as instituições alemãs, em 2013, com o objetivo de difundir o assunto pelo país [5].

De acordo com [5], a Indústria 4.0 possibilita implementar tecnologias, como a visão computacional, robótica avançada, inteligência artificial e Internet das Coisas (IoT). Com o avanço dessas tecnologias, novas bibliotecas, frameworks, softwares e equipamentos passaram a ser desenvolvidos para diversos setores.

Neste contexto percebeu-se a possibilidade de unir as ferramentas das Indústria $4.0 \mathrm{com}$ os processos convencionais da metrologia, possibilitando a modernização e inovação dos processos. O termo
Metrologia 4.0 faz referência ao uso das tecnologias da quarta revolução industrial, com o objetivo de garantir maior eficiência, confiabilidade e independência humana dos processos. Além disso, esse desenvolvimento traz a melhoria contínua, análise de riscos e tomada de decisões em tempo real e de forma simplificada [3].

Para implementar a Metrologia 4.0 e possibilitar a inovação do processo de calibração, pensou-se em integrar a visão computacional com o processo de calibração de trenas.

Segundo [2], trenas de fita de aço são instrumentos de medição que possuem uma fita graduada em todo o seu comprimento. A calibração da trena envolve a comparação da escala da trena com um padrão, normalmente utilizado a régua graduada, através de um instrumento com escala para medição da diferença entre o mesmo traçado da trena e do padrão.

Para auxiliar no desenvolvimento do projeto está sendo utilizada a biblioteca OpenCV [6]. A OpenCV é uma biblioteca de código aberto com diversos algoritmos para o desenvolvimento de visão computacional.

\section{SOLUÇÃO PROPOSTA}

A solução proposta envolve a utilização de Visão Computacional para analisar capturas de uma regra graduada padrão de bancada de calibração, denominada no trabalho de "régua padrão", e a trena a qual se deseja calibrar, comparando suas graduações com as da régua padrão.

A régua padrão e a trena serão analisadas através de uma câmera de vídeo e a partir das capturas serão caracterizadas as graduações da régua padrão e da trena. A Figura 1 ilustra a estrutura utilizada.

Para identificar as graduações da régua padrão e da trena está em desenvolvimento um método para identificar e caracterizar cada graduação o mais preciso possível. Embora exista uma função para a detecção de retas na imagem, ela não é precisa o suficiente, por exemplo, com o método disponível na biblioteca OpenCV. Também se faz necessário aplicar um método de OCR (Optical character recognition - Reconhecimento ótico de caracteres) para reconhecer o valor de cada graduação. A Figura 2 ilustra essa caracterização, onde na cor laranja se encontra a linha projetada na imagem capturada da câmera, bem como a identificação da graduação que ela representa.

A Figura 2 exagera a inclinação da régua para ilustrar que angulações podem estar presentes na aplicação. Sendo assim não é possível considerar apenas encontrar o valor no eixo "x" em um plano cartesiano e somente variar a reta no eixo "y". Para isso será avaliada inicialmente a aplicação da equação reduzida da reta, apresentada na equação 1 . 


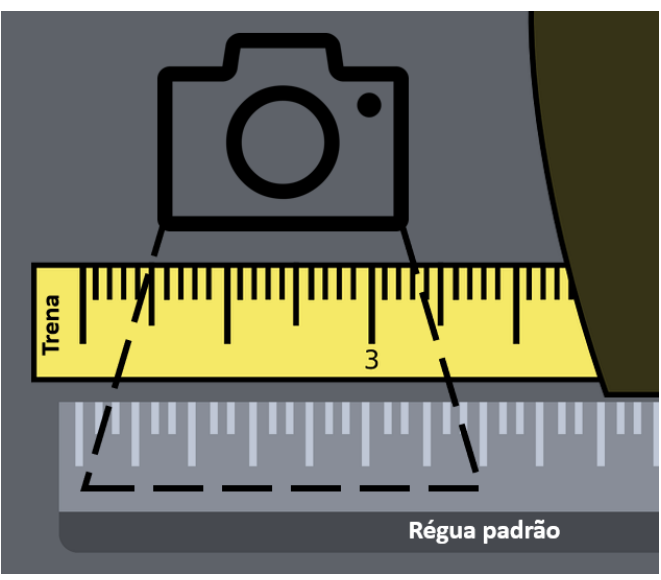

Figura 1: Sistema de visão computacional para calibração de trenas

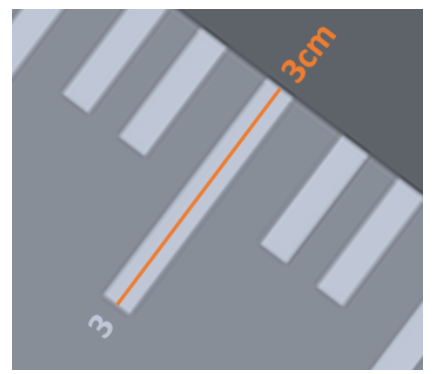

Figura 2: Interpretação feita em uma graduação da régua

$$
y=m x+c
$$

, sendo $x$ e $y$ pontos pertencentes à reta, $m$ o coeficiente angular da reta e $c$ o coeficiente linear.

Através da equação reduzida da reta será possível estender as graduações da régua padrão e da trena, para depois calcular as distâncias entre as graduações.

A correta caracterização da graduação envolve determinar precisamente dois pontos no centro da graduação, elemento desafiador da proposta e imprescindível, uma vez que se desenvolve uma ferramenta de auxílio para a calibração.

Sendo assim, após caracterizada a régua padrão e a trena, as graduações são estendidas até se cruzarem, para então comparar as graduações de cada uma e determinar as diferenças (distâncias) encontradas na trena com relação a régua padrão. A Figura 3 esquematiza a solução proposta.

Uma vez que a régua padrão possui normalmente tamanho inferior a das trenas a serem calibradas, o sistema precisa auxiliar o operador na avaliação de cada parte da trena. Nesse sentido é preciso armazenar qual a última graduação da trena considerada na comparação, para esta graduação ser a inicial do próximo segmento de análise. A identificação da graduação é feita com o auxílio do OCR na numeração da graduação.

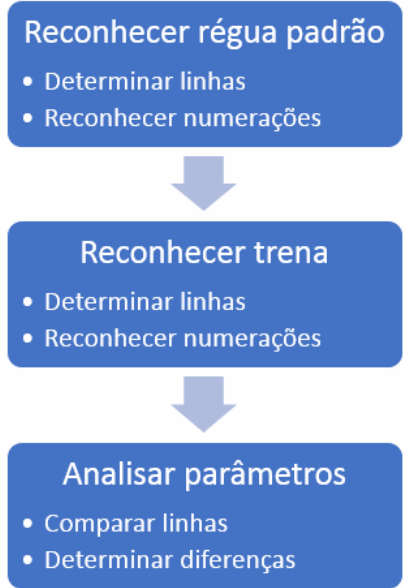

Figura 3: Esquema da solução proposta.

\section{CONSIDERAÇÕES FINAIS}

Uma calibração confiável exige a correta caracterização da graduação da régua padrão e da trena. Para isso é preciso aprimorar a forma como é determinado o centro da graduação, uma vez que a imagem capturada possui imperfeições que afetam a correta definição. O trabalho ainda precisa determinar a resolução mínima necessária (podendo variar a qualidade da câmera ou distância da captura) e estrutura física para fixação da câmera, visando alcançar a melhor identificação das graduações possível.

O objetivo desse trabalho é desenvolver um sistema não para a mensuração utilizando apenas uma câmera. Devido a precisão necessária, o trabalho considera que a régua padrão é um elemento indispensável para a aplicação e, nesse sentido, o processo de calibração deve seguir as normas existentes quanto à temperatura do ambiente e demais requisitos. Além disso, como a régua padrão é o elemento indispensável na proposta, é considerado que não é necessário fazer a calibração para o tipo da câmera, sendo cada graduação da régua padrão utilizada na comparação.

\section{REFERÊNCIAS}

[1] CONMETRO. 2017. Diretrizes estratégicas para a metrologia brasileira 2018-2022.

[2] Associação Brasileira de Normas Técnicas. 2012. ABNT NBR10123: instrumentos de medição e controle - trena de fita de aço - requisitos.

[3] Teresinha Freire. 2018. A mais nova "medida". https://issuu.com/editora_valete/ docs/ci240. Acessado em: 2019-10-08.

[4] INMETRO. 2012. Vocabulário Internacional de Metrologia: conceitos fundamentais e gerais e termos associados.

[5] Confederação nacional da indústria. 2016. Desafios para a indústria 4.0 no Brasil.

[6] OpenCV. 1999. OpenCV. https://opencv.org. Acessado em: 2019-10-08. 